Szymon PASKO ${ }^{\text {), }}$, Tomasz BISKUP ${ }^{1)}$, Carsten BUEHRER ${ }^{2)}$, Bogusław GRZESIK ${ }^{\text {1) }}$, Josien ROESTKRIJGSMAN $^{3)}$, Jarosław MICHALAK ${ }^{\text {) }}$, Mariusz STĘPIEN ${ }^{1)}$, Marcin ZYGMANOWSKI ${ }^{\text {l) }}$

${ }^{1)}$ Politechnika Śląska, Katedra Energoelektroniki Napędu Elektrycznego i Robotyki

${ }^{2)}$ KEMA NEDERLAND B. V

3) THRITHOR GmbH

\title{
COMPARISON OF SMES AND SCES BASED POWER CONDITIONING SYSTEMS
}

Summary. The selection of the less expensive Power Conditioning System (PCS) is the aim of the work where two types of PCS are taken into consideration. The first type of PCS is based on Superconducting Magnetic Energy Storage (SMES) while the second one is based on Supercapacitor Energy Storage (ScES). The comparison is based on installed power as the criterion. An illustrative example is given in the work.

\section{PORÓWNANIE SMES I SCES BAZUJĄCYCH NA KONDYCJONERZE ENERGII}

Streszczenie. W artykule przedstawiono porównanie kondycjonerów energii: kondycjonera zawierającego cewkę nadprzewodzącą (SMES) z kondycjonerem energii z superkondensatorami (ScES). Głównym kryterium analizy porównawczej kondycjonerów energii (PCS) jest moc zainstalowana. Analiza porównawcza ma na celu określenie, który $z$ omawianych systemów jest tańszym i lepszym rozwiązaniem służącym do poprawy jakości energii.

\section{INTRODUCTION}

The interest in Power Quality (PQ) issues constantly increases due to loads, which are very sensitive to $P Q$ disturbances. The main causes of $P Q$ reduction are nonlinear loads and also faults in the grid. One of the solutions to mitigation a PQ problem is Power Conditioning Systems (PCS) with Superconducting Magnetic Energy Storage (SMES), or Supercapacitor Energy Storage (ScES). SMES-based and ScES-based Power Conditioning Systems are in short abbreviated as PCS-M and PCS-C, respectively. The comparison of these two types of PCS-M with PCS-C is the aim of the work.

Such comparison is needed to find out which of these two solutions is the better one. The installed power is an essential quantitative criterion because it makes possible to estimate the capital cost of PCS that can be treated as a basis for estimation of the return time when the operating costs are assumed to be negligible. The installed power is calculated for the power part of the PCS. The total installed power is the sum of the installed power of each PCS component. The installed power is calculated for the worst case of operation of the PCSs. 


\section{POWER CONDITIONING SYSTEM (PCS)}

The PCS is a system that keeps PQ of electrical energy at the needed level. It operates as: i) an uninterruptible power source (UPS) of high dynamics, ii) compensator of reactive power and, iii) a harmonic filter, iv) ensures a symmetrical current that flows from the grid.

UPS operation takes place after a voltage disturbance occurs. During the UPS operation the PCS delivers energy to the protected load exclusively from the energy storage since the PCS is disconnected from the grid. It ensures the continuous supply of power for protected loads ensuring normal operation. It is possible to distinguish several kinds of voltage disturbances. They are: i) voltage dips, ii) voltage harmonics, iii) surges, iv) voltage interruptions. When the PCS operates like reactive power source or harmonic filter it is connected to the grid. These modes are usually easy to obtain since the power electronic converter being somewhat more complicated can operate as a reactive source and at the same time as a harmonic filter. It means that it does not influence the grid taking only the current fundamental harmonic that in addition is in phase with the grid voltage.

The structure of two types of PCS is depicted in Fig. 1 and described in the next section.

\subsection{Description of PCS-M and PCS-C}

The PCS-M is in Fig.1a, while the PCS-C is depicted in Fig. 1b. Each one contains: i) the Switch, ii) CL filter, iii) the AC-DC inverter, iv) the DC-DC converter and the energy storage. The switch disconnects PCS from the grid when the voltage dip occurs. It makes the energy flow from the storage only to protected load, not to the grid that represents a low impedance in such a case.

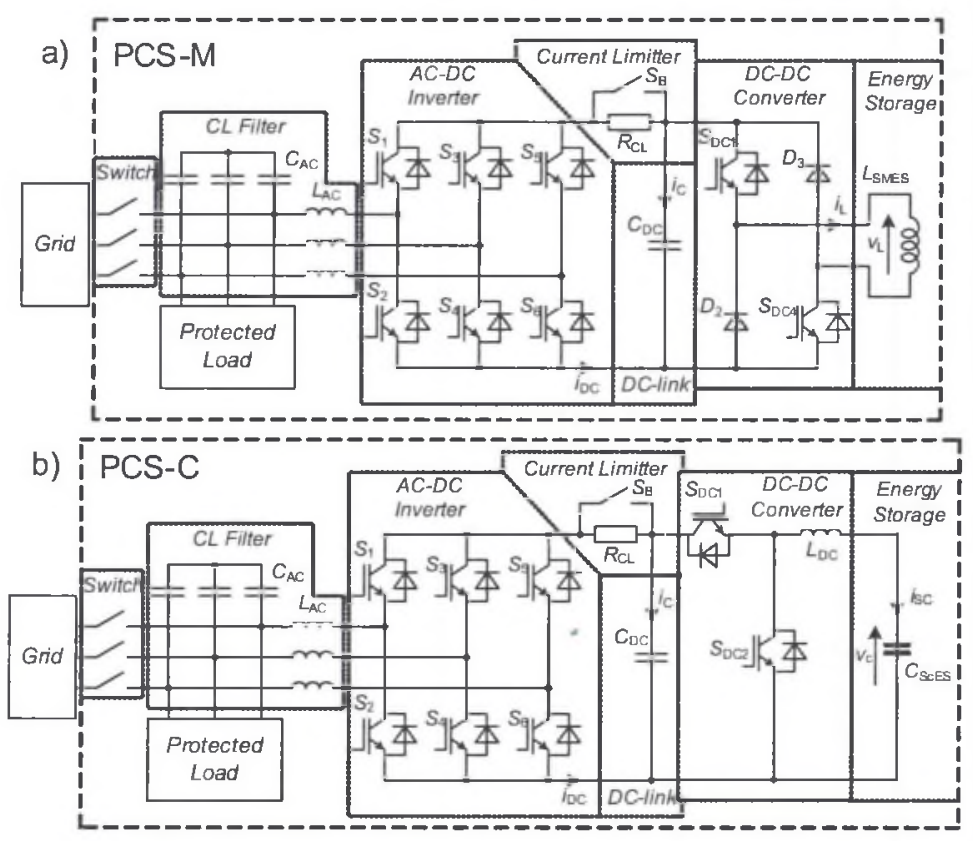

Fig. 1. a) Schematic diagram of: a) PCS-M, b) PCS-C Rys. 1. a) Schemat elektryczny: a) PCS-M, b) PCS-C 
The AC-DC inverter and the DC-DC converter operate as an interface between the energy storage and the protected load/grid, thus they should be bi-directional. The AC-DC inverter (PWM, $3 \mathrm{kHz}$ of carrier) keeps the grid currents approximately sinusoidal and in phase with the voltage of the grid. A CL filter is an interface between the AC-DC inverter and protected load/grid. The inductance $\mathrm{L}_{\mathrm{AC}}$ is responsible for shaping its current [1], [2], [3], [5].

The DC-DC converter structure for each case is different. In PCS-M the DC-DC converter (Fig. 1a) controls DC link voltage and the SMES current.

For PCS-C this DC-DC converter (Fig. lb) also controls DC link voltage and ScES voltage. It operates as a bi-directional buck/boost converter [4], [5]. The operations of DC-DC converters the for both considered cases are described in the next chapters of this paper [2], [6].

\section{COMPARISON CONDITIONS}

The comparative analysis has to be carried out for the following assumptions:

i) two types of PCS are compared, PCS-M and PCS-C, ii) both PCSs are connected to the same grid of given voltage and frequency, iii) the following parts and parameters are identical:

- Switch, CL filter and AC-DC Inverter, current limiter, DC-link capacitor,

- Load,

- Rated power of charging and discharging energy storage,

- Rated energy stored.

iv) DC-DC Converters and energy storages are different, v) comparison analysis is carried out for the worst case of operation, that is:

- PCS is in UPS operation mode with storage discharging at the power that is the rated power of protected load

- The whole energy is transferred from the storage to the protected load at its rated power that is constant.

vi) the analysis is illustrated with a numerical example presented below.

\subsection{Discharging of SMES}

The installed power of SMES and DC-DC converter can be calculated basing on the description of discharging the SMES. The superconducting coil $L_{S M E S}$ stores the maximum energy $E_{\mathrm{L} 0}$ that is given by (1). The rated coil current $I_{\mathrm{L} 0}$, before the beginning of discharging, flows through the superconducting coil which is short-circuited by the DC-DC converter

$$
E_{\mathrm{L} 0}=L_{\mathrm{SMES}} \frac{I_{\mathrm{L} 0}{ }^{2}}{2} .
$$

The rated coil current $I_{\text {Lo }}$ has to be high enough to ensure the discharging of the coil at the assumed maximum power $P$ for the assumed time $t_{1}$. During the discharging the coil at the constant power $P$ the coil current is decreasing from its rated value $I_{\mathrm{L} 0}$. The discharging takes place until the voltage applied to the coil reaches its maximum value $V_{L I}=V_{C D C}-$ Fig. $2 \mathrm{a}$.

The energy of the coil $e_{\mathrm{L}}$ decreases linearly due to equation (2) (see in Fig. 2a). The coil current change is given by formula (3)

$$
e_{\mathrm{L}}=E_{\mathrm{L} 0}-P t \text {, }
$$




$$
i_{\mathrm{L}}=\sqrt{\frac{2 E_{\mathrm{L} 0}-2 P t}{L_{\mathrm{SMES}}}} .
$$

The voltage $v_{\mathrm{L}}$ increases as given by equation (4). The voltage is created by the DC-DC converter with switching period much smaller than the discharging time $t_{1}$

$$
v_{\mathrm{L}}=\frac{P}{i_{\mathrm{L}}}=\frac{P}{\sqrt{\frac{2 E_{\mathrm{L} 0}-2 P t}{L_{\mathrm{SMES}}}}} .
$$

The process of discharging is illustrated in Fig. 2a by energy $e_{\mathrm{L}}$, current $i_{\mathrm{L}}$ and voltage $v_{\mathrm{L}}$ that are time dependent. In this figure $E_{\mathrm{L} 0}, I_{\mathrm{L} 0}$ are defined at the beginning of the discharging process whereas $V_{\mathrm{L}}$ is the value of $v_{\mathrm{L}}$ at the end of the discharge.

\subsection{Discharging of ScES}

A description of discharging ScES and the DC-DC converter is necessary for calculations of the installed power for ScES and the DC-DC converter. The supercapacitor tank characterized by the capacitance $C_{\mathrm{SC}}$ stores the maximum energy $E_{\mathrm{SC} 0}$ that is expressed by (5). Before the beginning of discharging the capacitor is charged to the rated voltage $V_{\text {SCO }}$ which should be as high as possible but not exceeding the DC link voltage

$$
E_{\mathrm{SC} 0}=C_{\mathrm{SC}} \frac{V_{\mathrm{SC} 0}^{2}}{2} \text {. }
$$

The supercapacitor tank discharge is described as a function of time with supercapacitor energy $e_{\mathrm{SC}}$, its voltage $v_{\mathrm{SC}}$ and current $i_{\mathrm{SC}}, \mathrm{cf}(6),(7),(8)$ and Fig. $2 \mathrm{~b}$

$$
\begin{aligned}
& e_{\mathrm{SC}}=E_{\mathrm{SC} 0}-P t, \\
& v_{\mathrm{SC}}=\sqrt{\frac{2 E_{\mathrm{SC} 0}-2 P t}{C_{\mathrm{SC}}},} \\
& i_{\mathrm{SC}}=\frac{P}{v_{\mathrm{SC}}}=\frac{P}{\sqrt{\frac{2 E_{\mathrm{SC} 0}-2 P t}{C_{\mathrm{SC}}}}} .
\end{aligned}
$$

The supercapacitor current expressed by (8) is controlled by the DC-DC converter operating at a relatively high switching frequency. One can observe the increasing of the supercapacitor current up to the maximum value $I_{\mathrm{SC}}$ where the process has to be finished because of the assumed discharging time $t_{1}$. This value of the current $i_{\mathrm{SC}}$ is a rated current. The amount of energy is the same as that in case of SMES.

The analysis of the discharging of energy storages is illustrated by an example given in the next subsections.

\subsection{Numerical description of discharging SMES and ScES}

The numerical analysis of PCS-M and PCS-C is performed for the following parameters: superconducting coil inductance $L_{\mathrm{SMES}}=12 \mathrm{H}$, supercapacitor tank capacitance $C_{\mathrm{SC}}=86.3 \mathrm{mF}$ (348 supercapacitors of $30 \mathrm{~F}, 2.3 \mathrm{~V}$ connected in series [7]), maximum continuous power 
drawn from the coil during the time $t_{1}=1 \mathrm{~s}$ is equal to $P=20 \mathrm{~kW}$. The rms line-to-line voltage in the mains is $V_{\mathrm{LL}}=400 \mathrm{~V}\left(V_{\mathrm{LLm}}=1.41 V_{\mathrm{LL}}=565 \mathrm{~V}\right)$, load is resistive-inductive with phase angle of $\varphi=45^{\circ}$. The DC-link capacitor voltage and the maximum voltage across the supercapacitor tank are set to $V_{\mathrm{DC}}=V_{\mathrm{L} 1}=V_{\mathrm{SC} 0}=750 \mathrm{~V}$. The inductance of the choke $L_{\mathrm{DC}}$ of the DC-DC converter in PCS-C is chosen $1 \mathrm{mH}$ and the switching frequency of this converter is set to $f_{\mathrm{SC}}=25 \mathrm{kHz}[5]$.
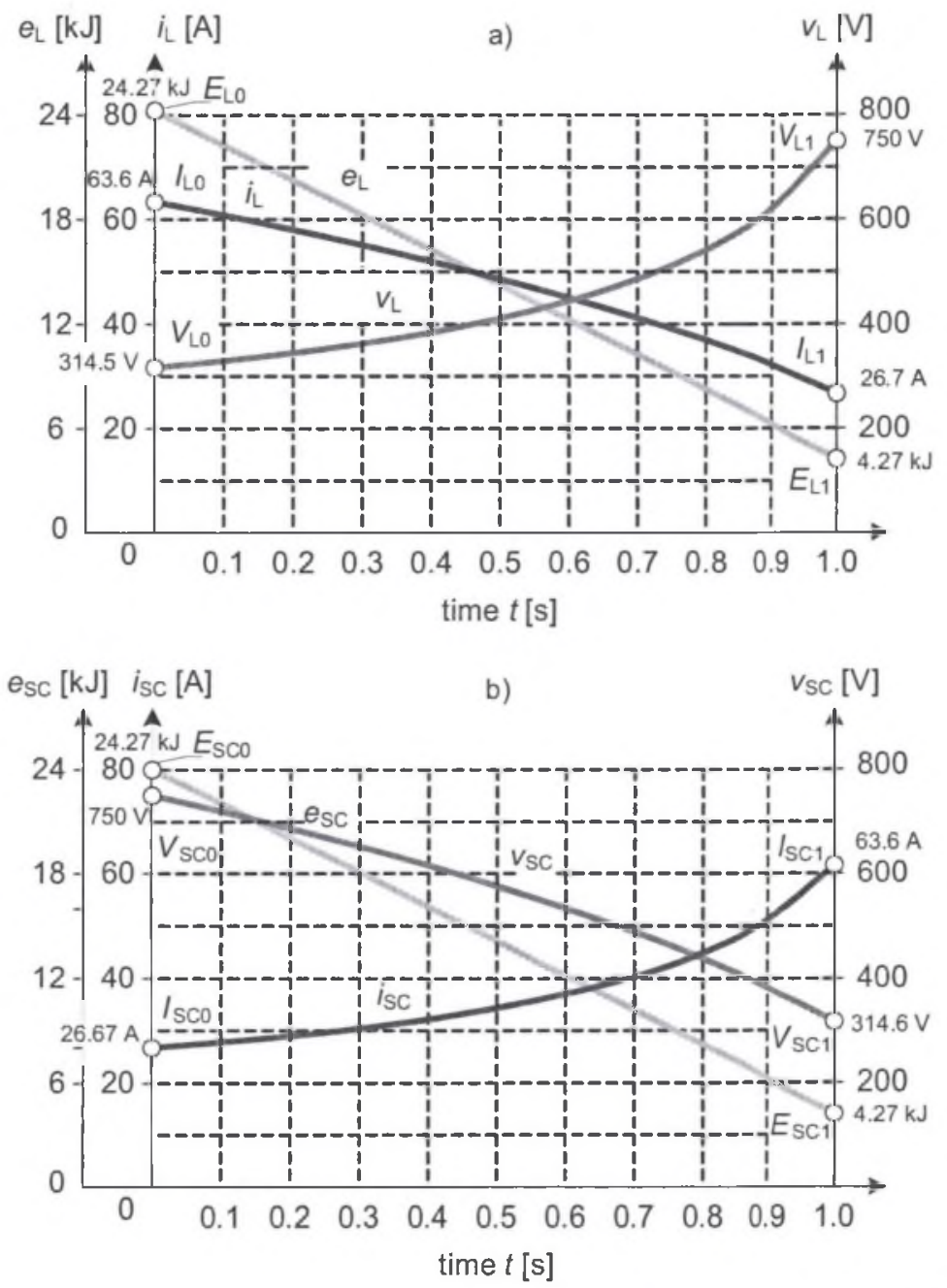

Fig. 2. Energy $e_{\mathrm{L}}, e_{\mathrm{SC}}$, current $i_{\mathrm{L}}, i_{\mathrm{SC}}$ and voltage $v_{\mathrm{L}}, v_{\mathrm{SC}}$ during discharging: a) for PCS-M, b) for PCS-C Rys. 2. Energia $e_{\mathrm{L}}, e_{\mathrm{SC}}$, prąd $i_{\mathrm{L}}, i_{\mathrm{SC}}$ i napięcie $v_{\mathrm{L}}, v_{\mathrm{SC}}$ podczas rozładowania: a) dla PCS-M, b) dla PCS-C

For PCS-M at the beginning of the discharging process the rated energy $E_{\mathrm{L} 0}$ and current $I_{\mathrm{L} 0}$ can be calculated by substituting the following data: $v_{\mathrm{L}}=V_{\mathrm{L} 1}=V_{\mathrm{DC}}, t=t_{1}$ into (4). For the comparison, under the same conditions the rated coil energy is also the same for the supercapacitor tank of PCS-C and is given by (9) 
146 Sz.Pasko, J.Michalak, T.Biskup, C.Buherer, B.Grzesik, J.Roest-Krijgsman, M.Zygmanowski.

$$
E_{\mathrm{L} 0}=E_{\mathrm{SC} 0}=\frac{P^{2} L_{\mathrm{SMES}}}{2 V_{\mathrm{Ll}}{ }^{2}}+P t_{1}=24.27 \mathrm{~kJ} .
$$

The maximum and minimum value of the coil current (from (3)) are equal to $I_{\mathrm{L} 0}=I_{\mathrm{SCl}}=63.6 \mathrm{~A}$ and $I_{\mathrm{LI}}=I_{\mathrm{SCO}}=26.67 \mathrm{~A}$. The minimum voltages across the coil and across the supercapacitor tank are given by (4) and (7), respectively. They are $V_{\mathrm{L} 0}=V_{\mathrm{SCI}}=314.5 \mathrm{~V}$. In Fig. 4 energy, current and voltage are presented for PCS-M and PCS-C.

\section{OPERATION OF THE DC-DC CONVERTER IN PCS-M}

\subsection{Operation of the DC-DC converter in PCS-M}

In the case of analysis performed in this paper the current $i_{\mathrm{DC}}$ (Fig. 3a) is assumed as a constant of $I_{\mathrm{DC}}=I_{\mathrm{L} 1}=26.6 \mathrm{~A}$.

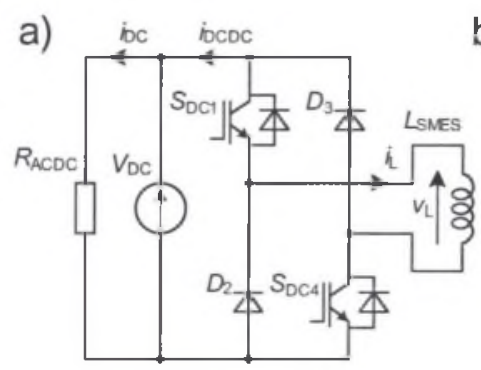

b)
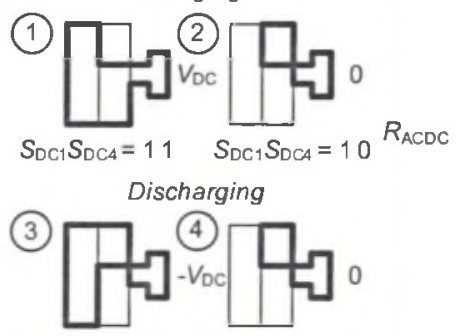

$S_{D C 1} S_{D C 4}=00 \quad S_{D C 1} S_{D C 4}=10$

Charging

Buck operation

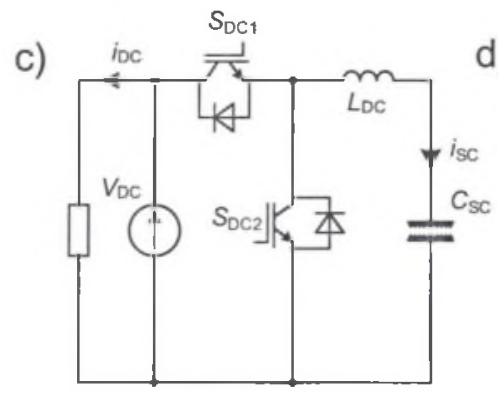

d) (1)
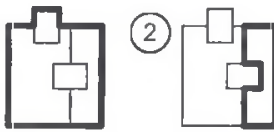

\section{Retaining}

Energy

$S_{\mathrm{DC} 1}$ and diode of $\mathrm{S}_{\mathrm{DC} 2}=1$ (3)

Discharging

Boost Converter

(4)
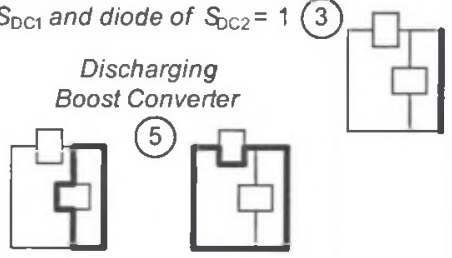

SDC2 and diode of $S_{D C 1}=1$

Fig. 3. DC-DC converters: a), b) - PCS-M; c), d) - PCS-C; a), c) - topologies, b), d) equivalent circuits

Rys. 3. Przekształtnik DC-DC: a), b) - PCS-M; c), d) - PCS-C; a), c) - topologia, b), d) - grafy

To maintain this constant current the DC-DC converter should modulate the coil current by varying the duty cycle of the DC-DC converter $D^{*}(10)$. Modulation processes of charging 
and discharging are expressed by four equivalent circuits presented in Fig. 3b. The resistor $R_{\mathrm{ACDC}}$ connected in parallel with the capacitor $C_{\mathrm{DC}}$ substitutes the $\mathrm{AC}-\mathrm{DC}$ converter

$$
D^{*}=\frac{t^{*}{ }_{\mathrm{eq} 3}}{T}=\frac{T-t^{*}{ }_{\mathrm{eq} 4}}{T}=\left|\frac{I_{\mathrm{DC}}}{i_{\mathrm{L}}}\right|,
$$

where: $t_{\text {eq } 3}$ and $t_{\text {eq } 4}^{*}$ are durations of the equivalent circuits 3 and 4 .

For the assumed $I_{\mathrm{L} 1}=26.6 \mathrm{~A}$ duty cycle at the beginning of the discharging coil, $t=0$ is $D^{*}{ }_{0}=0.42$ while for the time $t_{1}, D_{1}^{*}=1$. The time dependent duty cycle $D^{*}$ is the same as the normalized voltage $v_{\mathrm{L}} / V_{\mathrm{DC}}$ as in Fig. $2 \mathrm{a}$.

\subsection{Operation of the DC-DC converter in PCS-C}

The DC-DC converter in PCS-C operates as a classical bi-directional buck or boost converter (depending on the direction of current flow). It is depicted in Fig. $3 \mathrm{c}, 3 \mathrm{~d}$. It operates as a boost converter when the current $i_{\mathrm{SC}}$ flows from supercapacitor $\mathrm{ScES}\left(i_{\mathrm{SC}}<0\right)$. The duty cycle of switching is described by (11)

$$
D^{* *}=\frac{t^{* *}{ }_{\text {eq } 4}}{T}=\frac{T-t^{* *}{ }_{\text {eq } 5}}{T}=\left|1-\frac{v_{\mathrm{SC}}}{V_{\mathrm{DC}}}\right|,
$$

where: $t^{* *}$ eq 4 and $t^{* *}$ eq 5 are durations of the equivalent circuits 4 and 5 . At the beginning of the discharging ScES its voltage is of $v_{\mathrm{SC}}=V_{\mathrm{DC}}=750 \mathrm{~V}$ and the duty cycle $D^{* *}{ }_{0}=0$, while at the end of discharging $\left(t=t_{1}\right)$ the duty cycle reaches the value of $D^{* *}{ }_{1}=0.42$.

\section{INSTALLED POWER}

The comparison of PCS-M with PCS-C is based on calculation of the total installed power. This parameter gives information about the capital cost of a given PCS. The total installed power of PCS is the sum of the installed power of each passive and active component the PCS is consisted of. The installed power of a single component is calculated as a product of the voltage that is across its terminals and the current that flows through it [3]. The installed power of the cooling system is not included in the total installed power of PCS. It should be noted that the relation between the installed power and price is different for different components. Having this information one can derive the price of a given component and the price of the whole system. Therefore the installed power can be used as an approximate criterion for comparison of PCSs. Calculation of the installed power is explained as follows. It is assumed that calculations are carried out for steady state and average and also rms values are taken over the mains voltage period. The factor of safety is not taken into consideration.

Switching devices. The installed power of switching devices like diodes or IGBTs is a product of the maximum value of the voltage across the component $V_{\text {Smax }}$, and average value of the conducted current $I_{\text {Sav }}$.

Capacitors. In the case of capacitors the installed power is a product of the rms value of the capacitor voltage, $V_{\mathrm{Cnns}}$ and $\mathrm{rms}$ value of the current, $I_{\mathrm{Crms}}$.

Inductors. For inductors the installed power is a product of the maximum possible voltage between the inductor terminals $V_{\mathrm{Lmax}}$ and rms value of the inductor current, $I_{\mathrm{Lrms}}$. 
148 Sz.Pasko, J.Michalak, T.Biskup, C.Buherer, B.Grzesik, J.Roest-Krijgsman, M.Zygmanowski.

Resistors. The installed power of resistors is equal to the power that can be dissipated by a resistor and is known as the resistor rated power. It is calculated as a square of the rms value of the current $I_{\text {Rrms }}$ multiplied by its resistance.

Breakers $S_{B}$. The installed power of breakers used in PCSs is a product of the maximum rms value of the conducted current $I_{\mathrm{Bmms}}$ and maximum voltage $V_{\mathrm{Lmax}}$ across its terminals.

\subsection{Installed power of SMES}

The installed power of the superconductive coil, SMES, is a product of the maximum voltage that can be applied to the coil and the rms value of the coil current. The maximum voltage across SMES is the $V_{\mathrm{DC}}$, that is $v_{\mathrm{L}}=V_{\mathrm{DC}}$. The current ripples in SMES are small enough to be neglected and the rms value of the coil current is approximately equal to the average value of this current. The installed power of the superconductive coil is as follows (12)

$$
P_{\mathrm{LSMES}}=V_{\mathrm{DC}} I_{\mathrm{L} 0}=2.38 V_{\mathrm{DC}} I_{\mathrm{DC}} \text {. }
$$

\subsection{Installed power of ScES}

For finding the installed power of a supercapacitor tank it is necessary to specify the rms value of the current that flows through the tank. The rms value of the current which is a sum of the triangular component and average value can be given by formula (13). The greatest value of this current appears at the end of discharging process $(t=1 \mathrm{~s})$

$$
I_{\mathrm{SCRMS}}=\sqrt{\frac{1}{3} \Delta I^{2}+I_{\mathrm{AV}}^{2}}=\sqrt{\frac{1}{3}\left(\frac{V_{\mathrm{SCl}}}{f_{\mathrm{SC}} L}\left(1-\frac{V_{\mathrm{SCl}}}{V_{\mathrm{SC} 0}}\right)\right)^{2}+{\frac{P}{V_{\mathrm{SC} 0}}}^{2}} .
$$

The installed power of ScES tank is expressed by (14)

$$
P_{\mathrm{SC}}=V_{\mathrm{SC} 0} I_{\mathrm{SCRMS}}=2.38 V_{\mathrm{DC}} I_{\mathrm{DC}} .
$$

\subsection{Installed power of DC-DC converter in PCS-M}

The installed power of switches such as IGBTs or diodes is a product of the maximum continuous voltage across the switch and the maximum average value of the switch current over the switching period. The voltage across each of switch as in the DC-DC converter is equal to $V_{\mathrm{DC}}$ but the switch current average value is different and depends on the duty cycle and the operation mode. From Fig. $3 \mathrm{~b}$ it appears that in charging mode switch $S_{\mathrm{DCl}}$ is still closed and conducts the coil current. The maximum average value of this switch current is equal to the rated coil current $I_{\mathrm{L} 0}$. Similar situation is for diode $D_{3}$, for discharging mode. For diode $D_{2}$ and transistor $S_{\mathrm{DC} 4}$ the maximum average current is equal to the maximum average value of DC-link current $I_{\mathrm{DC}}$. The installed power of the DC-DC converter switches $P_{\mathrm{DCDC}}$ is given by (15)

$$
P_{\mathrm{DCDC}}=V_{\mathrm{DC}}\left(2 I_{\mathrm{DC}}+2 I_{\mathrm{L} 0}\right)=6.77 V_{\mathrm{DC}} I_{\mathrm{DC}}
$$




\subsection{Installed power of DC-DC converter in PCS-C}

The voltage across each switch in the DC-DC converter is equal to $V_{\mathrm{DC}}$ and the current maximum average values of switch $\mathrm{S}_{\mathrm{DC} 1}$ and $\mathrm{S}_{\mathrm{DC} 2}$ are described by (16) and (17), respectively

$$
\begin{aligned}
& I_{\mathrm{SDC} 1}=\frac{P}{V_{\mathrm{DC}}}=I_{\mathrm{DC}}, \\
& I_{\mathrm{SDC} 2}=\frac{P}{V_{\mathrm{SCl}}} \cdot\left(1-\frac{V_{\mathrm{SCl}}}{V_{\mathrm{DC}}}\right)=1.38 I_{\mathrm{DC}} .
\end{aligned}
$$

The average value of $\mathrm{S}_{\mathrm{DC} 1}$ current is independent of the voltage across the supercapacitor tank. The average value of switch $\mathrm{S}_{\mathrm{DC} 2}$ current is the highest at the end of discharging process $\left(t=t_{1}\right)$. The installed power of DC-DC converter switches is described by formula (18)

$$
P_{\mathrm{SCDCDC}}=V_{\mathrm{DC}}\left(I_{\mathrm{SDC} 1}+I_{\mathrm{SDC} 2}\right)=2.38 V_{\mathrm{DC}} I_{\mathrm{DC}}
$$

\subsection{Installed power of inductor $L_{\mathrm{DC}}$ in PCS-C}

The rms value of the current in the inductor $L_{\mathrm{DC}}$ equals the average value of the ScES current. Its maximum voltage is the same as the maximum voltage across the capacitor ScES. Therefore the installed power of the inductor is the same as that of ScES.

\subsection{Installed power of DC-link capacitor in PCS-M}

The voltage across the DC-link capacitor is constant and is equal to $V_{\mathrm{DC}}$. The installed power in case of the DC-link capacitor is a product of the maximum rms value of its current $I_{\text {CLrms }}$ and voltage $V_{\mathrm{DC}}$. The rms value of the DC-link capacitor current in PCS-M is expressed by (19) and its waveform is presented in Fig. 4. The maximum rms value of the capacitor current occurs at time $t=0 \mathrm{~s}$ when the coil current is equal to $I_{\mathrm{L} 0}$ for the duty cycle $D^{\circ}{ }_{0}=0.42$

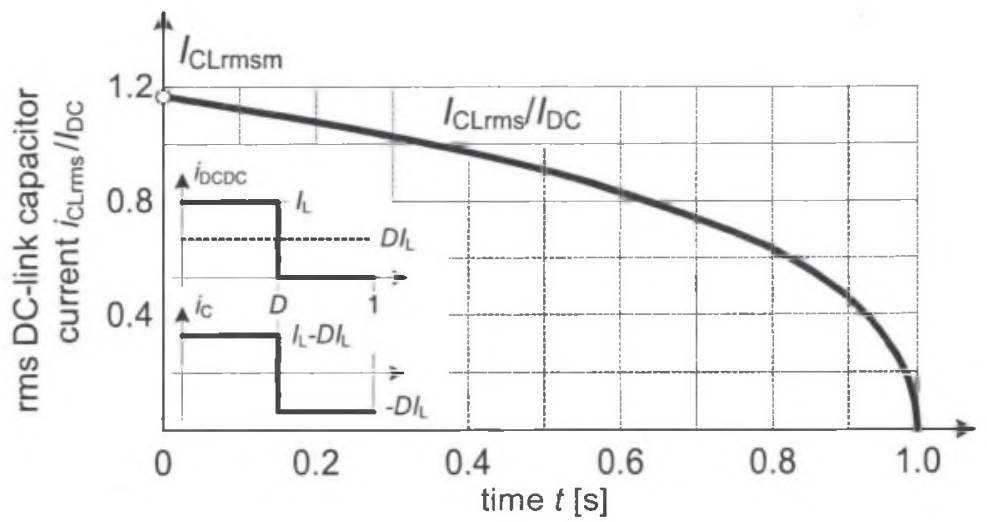

Fig. 4. The rms value of DC-link capacitor current during for discharging coil

Rys. 4. Wartość skuteczna prądu w obwodzie pośredniczącym DC-link podczas rozładowania cewki 


$$
I_{\mathrm{CLrms}}=\sqrt{\left(i_{\mathrm{L}}-i_{\mathrm{L}} D^{*}\right)^{2} D^{*}+\left(i_{\mathrm{L}} D^{*}\right)^{2}\left(1-D^{*}\right)} .
$$

Substituting (10) into (19) one obtains (20)

$$
I_{\text {CLms }}(t)=I_{\mathrm{DC}} \sqrt{\frac{i_{\mathrm{L}}(t)}{I_{\mathrm{DC}}}-1},
$$

The maximum rms value of the capacitor current $I_{\mathrm{CL} \text { rmsm }}$ is equal to $1.18 I_{\mathrm{DC}}$ and appears at $t=0 \mathrm{~s}$. The installed power of the DC link capacitor is given by (21)

$$
P_{\mathrm{CL}}=V_{\mathrm{DC}} I_{\mathrm{CLrmsm}}=1.18 V_{\mathrm{DC}} I_{\mathrm{DC}} \text {. }
$$

\subsection{Installed power of DC-link capacitor in PCS-C}

Similar analysis is carried out for the DC-link capacitor in PCS-C. The rms value of the capacitor current is calculated from equation (22). Contrary to PCS-M the current maximum rms value occurs at the end of the discharging $\left(t=t_{1}\right)$ therefore $I_{\mathrm{CSC} n s m}$ is equal to $1.18 I_{\mathrm{DC}}$. The voltage across the capacitor is equal to $V_{\mathrm{DC}}$. The installed power of the DC-link capacitor is the same as in case of PCS-M, given by (23)

$$
\begin{gathered}
I_{\mathrm{CSC} r \mathrm{~ms}}=\sqrt{\left(I_{\mathrm{SC} 1}-I_{\mathrm{DC}}\right)^{2} \frac{V_{\mathrm{SC} 1}}{V_{\mathrm{DC}}}+I_{\mathrm{DC}}{ }^{2}\left(1-\frac{V_{\mathrm{SC} 1}}{V_{\mathrm{DC}}}\right)}=1.18 I_{\mathrm{DC}}, \\
P_{\mathrm{CSC}}=V_{\mathrm{DC}}^{r} I_{\mathrm{CSC} m \mathrm{~s}}=1.18 V_{\mathrm{DC}} I_{\mathrm{DC}} .
\end{gathered}
$$

\subsection{Installed power of AC-DC converter}

The installed power of the AC-DC converter is a sum of the installed powers of all six switches (e.g., IGBT). The voltage across each switch is equal to $V_{\mathrm{DC}}$. Because of the internal body diode of the switch, the switch with its diode is bi-directional. Therefore the absolute value of this current is taken for calculation of its installed power. The AC-DC converter operates under the PWM strategy, which results in sinusoidal AC currents. The maximum instant value of the switch current $I_{\mathrm{Sm}}$ (amplitude) occurs when the PCS operates in UPS mode and is given by equation (24) where $I_{\mathrm{RL}}$ is the load current

$$
I_{\mathrm{Sm}}=I_{\mathrm{RLm}}=\sqrt{2} \frac{P}{\sqrt{3} V_{\mathrm{LL}} \cos (\varphi)}=2.16 I_{\mathrm{DC}} .
$$

In Fig. 5 one phase-leg of the AC-DC converter is depicted. From this figure it can be seen that $\mathrm{AC}$ current $i_{\mathrm{AC}}$ is a sum of the switch currents $i_{\mathrm{S} 1}$ and $i_{\mathrm{S} 2}$.

Assuming that PWM strategy results in the symmetrical sinusoidal current $i_{\mathrm{AC}}$ as in Fig. $5 \mathrm{~b}$, the average switch current is described by (25). The installed power of AC-DC converter switches is expressed by (26) 


$$
\begin{gathered}
I_{\mathrm{SAV}}=\frac{1}{\pi} I_{\mathrm{Sm}}=0.69 I_{\mathrm{DC}}, \\
P_{\mathrm{ACDC}}=\frac{6}{\pi} V_{\mathrm{DC}}^{\prime} I_{\mathrm{Sm}}=4.13 V_{\mathrm{DC}} I_{\mathrm{DC}} .
\end{gathered}
$$

a)

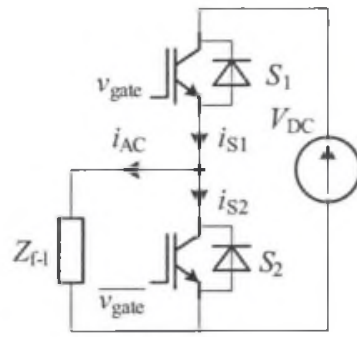

b)

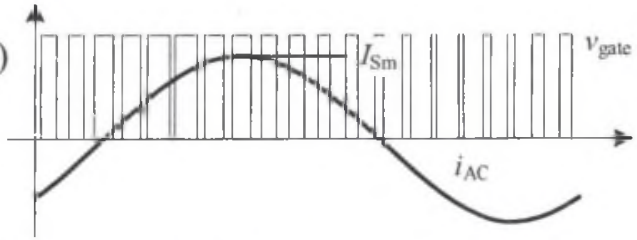

c)

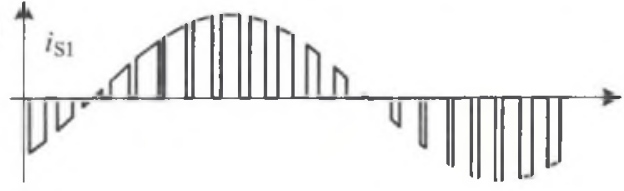

d)

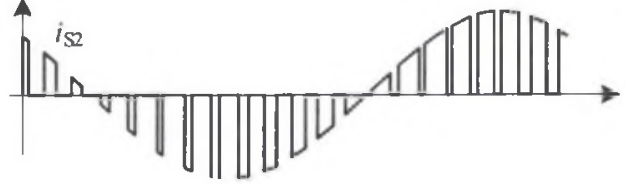

Fig. 5. One phase leg of AC-DC converter: a) topology, b) gating signal $v_{\text {gate }}$ with $\mathrm{AC}$ current $i_{\mathrm{AC}}, \mathrm{c}$ ) and d) switches currents $i_{\mathrm{S} 1}$ and $i_{\mathrm{S} 2}$ respectively

Rys. 5. Pojedyncza gałąź przekształtnika $\mathrm{AC}-\mathrm{DC}$ : a) topologia, b) sygnał sterujący $v_{\text {gatc }} \mathrm{z}$ prądem $\mathrm{AC} i_{\mathrm{AC}}$, c), d) prąd przelączania $i_{\mathrm{S} 1} i i_{\mathrm{S} 2}$ odpowiednio

\subsection{Installed power of CL filter inductors $\boldsymbol{L}_{\mathrm{AC}}$}

The maximum voltage across line inductors is a half of the sum of the DC-link voltage $V_{\mathrm{DC}}$ and the amplitude of the line-to-line voltage $V_{\mathrm{LLm}}$. The maximum rms value of the line inductor current is the rms value of the load current written in (27)

$$
I_{\mathrm{RLms}}=\frac{P}{\sqrt{3} V_{\mathrm{LL}} \cos (\varphi)}=1.53 I_{\mathrm{DC}} .
$$

Thus, the installed power of the line inductors is as follows:

$$
P_{\mathrm{LAC}}=3\left(\frac{V_{\mathrm{DC}}+V_{\mathrm{LLm}}}{2}\right) I_{\mathrm{RL} r \mathrm{~ms}}=4.03 V_{\mathrm{DC}} I_{\mathrm{DC}} \text {. }
$$

\subsection{Installed power of $\mathrm{CL}$ filter capacitors $C_{\mathrm{AC}}$}

The reason why capacitors $C_{\mathrm{AC}}$ are placed in parallel to the load is to smooth the voltage in UPS mode. The fundamental component of the capacitor current should be much smaller than the fundamental current of the load. All the higher current harmonics generated by the AC-DC converter should be conducted by $C_{\mathrm{AC}}$. For calculation of the installed power of filter capacitors Matlab-Simulink simulation was used. In order to assume a relatively small current 
152 Sz.Pasko, J.Michalak, T.Biskup, C.Buherer, B.Grzesik, J.Roest-Krijgsman, M.Zygmanowski.

flowing through the capacitor some iteration was made. The results of the exemplary calculations are $C_{\mathrm{AC}}=20 \mu \mathrm{F}, I_{\mathrm{CACrms}} / I_{\mathrm{RI} \text {.rms }}=0.03(1.75 \mathrm{~A}$ at $2.4 \mathrm{kHz})$. The installed power is expressed by equation (29)

$$
P_{\mathrm{CAC}}=3 \frac{V_{\mathrm{LL}}}{\sqrt{3}} I_{\mathrm{CAC} \text { ms }}=0.05 I_{\mathrm{DC}} V_{\mathrm{DC}} \text {, }
$$

\subsection{Installed power of current limiter $S_{\mathrm{B}}$}

The installed power of the current limiter $S_{\mathrm{B}}$ is a product of the maximum value of the voltage across it and the rms value of the current that is conducted by the breaker. The maximum voltage occurs before the capacitor $C_{\mathrm{DC}}$ charging starts. It equals the maximum lineto-line voltage, $V_{\mathrm{LLm}}$. The installed power of the breaker $S_{\mathrm{B}}$ is calculated from (30).

The installed power of the resistor $R_{\mathrm{CL}}$ is not calculated here because of the fact that this resistor limits current only during a short time (one or a few periods of the grid) and the installed power of this component compared to other components is negligible

$$
P_{\mathrm{B}}=V_{\mathrm{LLm}} I_{\mathrm{DC}}=0.75 V_{\mathrm{DC}} I_{\mathrm{DC}}
$$

\subsection{Installed power of the switch}

The installed power of the switch is a product of the maximum value of the voltage across it, which is equal to the grid phase voltage, and rms value of the load current active component. The installed power of the switch is expressed by (31)

$$
P_{\mathrm{R}}=\frac{V_{\mathrm{LLm}}}{\sqrt{3}} \frac{P}{\sqrt{3} V_{\mathrm{LL}}}=\frac{\sqrt{2}}{3} V_{\mathrm{DC}} I_{\mathrm{DC}}=0.47 V_{\mathrm{DC}} I_{\mathrm{DC}} \text {. }
$$

\section{TOTAL INSTALLED POWER OF PCS}

The results of calculations of the installed power for each specified part of the PCS are gathered in Table I. There is also given the total installed power for the both PCSs.

Results of the calculations of installed power

\begin{tabular}{|l|c|c|}
\hline \multirow{2}{*}{ Component } & \multicolumn{2}{|c|}{ Installed Power [kVA] } \\
\cline { 2 - 3 } & PCS-M & PCS-C \\
\hline AC-DC converter & 82.7 & 82.7 \\
\hline DC-DC converter & 135.4 & 47.7 \\
\hline DC inductor & --- & 47.7 \\
\hline DC-link capacitor & 23.5 & 23.5 \\
\hline Energy Storage & 47.7 & 47.7 \\
\hline Filter inductor & 80.6 & 80.6 \\
\hline Filter capacitor & 1.0 & 1.0 \\
\hline Current Limiter & 15.1 & 15.1 \\
\hline Switch & 15.1 & 15.1 \\
\hline Total installed power & $\mathbf{3 9 5 . 4}$ & $\mathbf{3 5 5 . 4}$ \\
\hline
\end{tabular}


In calculation of the installed power only a bare coil was taken into account without cryoand vacuum facilities. It makes somewhat unrealistic comparative estimation, especially for PCS-M of small rated power and energy. The total installed power is higher for PCS-M. It essentially stems from the difference of the installed power of DC-DC converters.

\section{GENERAL COMPARISON BETWEEN SMES AND SCES}

Comparison reflects certain real PCS-M and PCS-C systems that were built in the laboratories of Department of Power Electronics, Electrical Drives and Robotics (KENER). The PCS-M is a system where SMES coil is placed inside the cryostat (Fig. 6a), to which a coldhead (Fig. 6c) is connected.

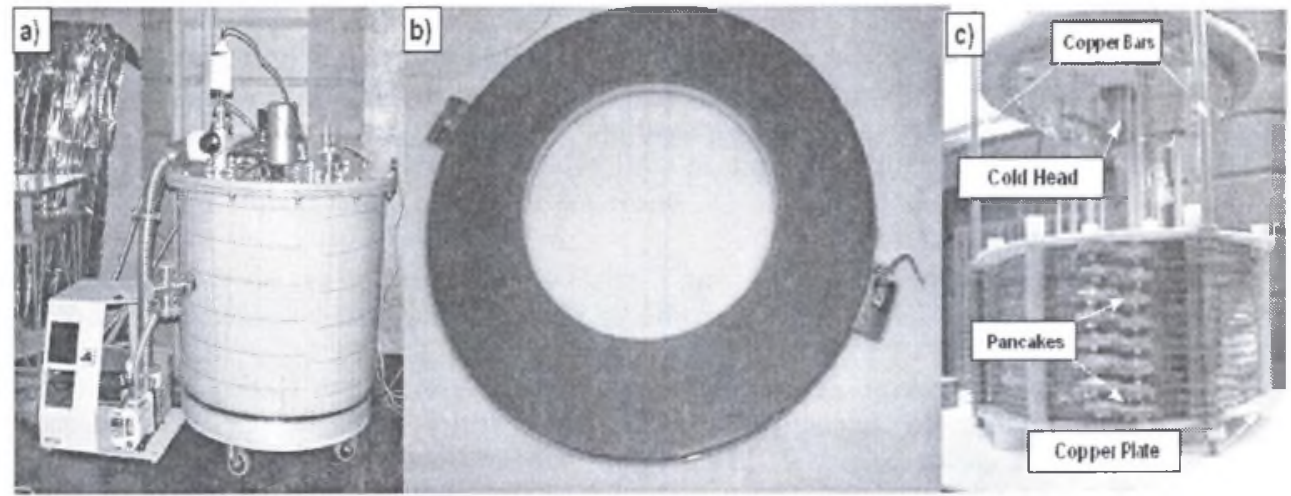

Fig. 6. a) Cryostat with SMES inside, b) pancake of SMES coil, c) HTS coil Rys. 6. a) Cewka SMES z kriostatem, b) pancake cewki SMES, c) cewka HTS

The SMES coil made of HTS wire (high temperature superconductor) is suspended by copper bars connected to a tripod that, in turn, is fixed to the coldhead. The coil is composed of 15 pancakes (Fig. $6 \mathrm{~b}$ and $6 \mathrm{c}$ ). HTS wire is of Bi 2223. The vacuum inside the cryostat and between the walls of the vacuum chamber insulate thermally the coil from the environment. Parameters of this PCS-M together with parameter of HTS coil are given in subsection "Numerical description ..." The temperature of the HTS coil is $25 \mathrm{~K}$ to $77 \mathrm{~K}$. The rated vacuum of the cryostat is $10^{-8}$ bar. Heat generated in HTS coil flows to the coldehead via copper bars see Fig. 6c.

Supercapacitor energy storage was designed for the sake of comparison analysis. It is built of 348 cells connected in series. Each one of $30 \mathrm{~F}$ and $2.3 \mathrm{~V}$ (NessCap [7]) of the rated voltage. It gives $86.3 \mathrm{mF}$. In order to have uniform distribution of the voltage across the tank of supercapacitors Zener diodes are used. The supercapacitor tank dimensions are $200 \mathrm{~mm} \mathrm{x}$ $210 \mathrm{~mm} \times 250 \mathrm{~mm}$. They are comparable with those of bare HTS coil.

\section{CONCLUSIONS}

From the comparison analyses one can drawn the following conclusions: i) The PCS-M installed power is somewhat higher than the PCS-C installed power of. It is the result of higher installed power of DC-DC converters, ii) In calculation of the installed power only a bare coil 
was taken into account without cryo- and vacuum facilities. It makes somewhat unrealistic comparative estimation especially for PCS-M of small rated power and energy. iii) In PCS-M the cooling system would increase the installed power whilst in PCS-S the balancing circuits, iv)The installed power does not reflect the energy consumption for cooling. This issue should be included in thorough analysis, vi) Live time of SMES case is much higher than that of ScES, v)The quality factor of SMES coil is much higher than that of ScES, vii) Until now the SMES has been more expensive than ScES, viii) The results were obtained for a relatively small rated power and rated energy. PCS-M is more advantageous in case of the need for electrical energy of the highest quality.

\section{REFERENCES}

1. Price A., Thjssen G., Symons P.: Elecricity storage, a solution in network operation, Distributech Europe 2000.

2. Doht H.-Ch., Hilscher M., Prescher K., Unterlass F.-J.: Design and Behaviour of a Superconducting Energy Management Systems (SEMS) for Industrial Power Quality Applications, EPE'99.

3. Biskup T., Bührer C., Grzesik B,. Krijgsman J, Michalak J., Pasko S., Zygmanowski M.: Comparison of Voltage and Current $A C$-DC Inverter Working in SMES Based PCS, EPE PEMC'04,Latvia

4. Biskup T., Bührer C., Grzesik B., Krijgsman J, Michalak J., Pasko S., Zygmanowski M.: Multilevel Converter for Power Conditioning System with SMES Przegląd Elektrotechniczny, pp. 609-614, June 2004.

5. Rufer A.: Solutions for storage of electrical energy, ANAE: Associazione Nazionale Azionamenti Elettrici, 14o Seminario Interattivo, Azionamenti elettrici : Evoluzione Tecnologica e Problematiche Emergenti, 23-26 March, Bressanone, Italy.

6. Casadei G., Grandi U., Reggiani G., Serra A., Tani A.: Behavior of a Power Conditioner for $\mu-S M E S$ Systems Under Unbalanced Supply Voltages and Unbalanced Loads. IEEE ISIE'99 Bled, Slovenia 12-16 July, 1999.

7. http:/www.nesscap.com/prod/details.htm\#1

The paper was presented on $11^{\text {th }}$ European Conference on Power Electronics and Application, 11-14 September 2005, Dresden, Germany

Wpłynęło do Redakcji dnia: 04 października 2005

Recenzent: Dr hab. inż. Zbigniew Hanzelka Prof. nadzw AGH 